\title{
The Ångström coefficient as an indicator of non-marine particles in ANAM (Advanced Navy Aerosol Model)
}

\author{
Jolanta Kusmierczyk-Michulec ${ }^{1}$ and Alexander M.J. van Eijk \\ TNO Defense, Safety and Security, PO Box 96864, The Hague, The Netherlands
}

\begin{abstract}
The Advanced Navy Aerosol model (ANAM), being a modified version of the Navy Aerosol Model (NAM), is a wellknown engineering tool providing a quick and reasonable estimate of the aerosol extinction in the marine near-surface environment on the basis of simple meteorological input data. The original NAM consists of 3 lognormal distributions, which describe freshly produced marine aerosols, aged marine aerosols (produced elsewhere and advected to the measurement site) and a background concentration of marine aerosols. The ANAM adds a $4^{\text {th }}$ lognormal mode to NAM to account for the largest marine particles. To account for non-marine particles, a special lognormal mode, called "dust mode" was included in NAM. The relative importance of the dust mode versus the marine background concentration is governed by a special input parameter known as the air mass parameter (AMP). Unfortunately, the AMP is ill-defined and the NAM user community has found it difficult to attribute a proper value to the AMP. This inconvenience became even more stressing when NAM was used for assessing aerosol extinction in the coastal zone. To overcome this inconvenience, a new approach is suggested which involves replacement of the AMP by the Ångström coefficient. The advantage is that the latter parameter can be directly measured and has a physical relation to the aerosol size distribution. When the particle size distribution is dominated by small particles, usually associated with pollution, the Ångström coefficients are high; in clear conditions they are usually low. Therefore this parameter is a good tracer of the aerosols originated over land and hence a good replacement for the AMP.
\end{abstract}

Keywords: Ångström coefficient, continental and industrial aerosols, ANAM, coastal zone, AMP

\section{INTRODUCTION}

Over the years considerable efforts have been made to express the aerosol extinction in the marine environment in terms of the meteorological conditions. In 1983 Gathman published the first version of the Navy Aerosol Model (NAM) which allowed predicting the marine aerosol concentration at ship's deck height for open ocean conditions. It was considered to be a milestone. NAM is available to the community via the USAF MODTRAN code (Kneizys et al., 1996).

The original NAM consists of 3 lognormal distributions, which describe freshly produced marine aerosols, aged marine aerosols (produced elsewhere and advected to the measurement site) and a background concentration of marine aerosols. The centre radii of the modes are nominally $0.03,0.24$ and $2.0 \mu \mathrm{m}$, but are adjusted as function of the relative humidity. The largest or third mode $(2 \mu \mathrm{m})$ consists of freshly produced marine aerosols. Its amplitude is determined by the instantaneous wind speed. The second mode $(0.24 \mu \mathrm{m})$ consists of marine aerosols that have spent some time in the atmosphere ("aged" marine mode) and have adjusted their size to the ambient conditions. Since these particles have been produced elsewhere and transported to their present location, the amplitude of the second mode is determined by the wind speed history. Finally, the first mode $(0.03 \mu \mathrm{m})$ consists of fine particles that constitute a marine background concentration. These particles have been aloft for such a long time that there presence is no longer governed by the instantaneous wind speed or even the wind speed history. Their concentration is given by the Air Mass Parameter (AMP), which can be given a value between 1 (low concentration) and 10 (high concentration). Since the AMP is not a measurable quantity, a relation between the AMP and the visibility have been established (and implemented in MODTRAN). However, this relation only holds for open ocean conditions.

\footnotetext{
${ }^{1}$ Contact information: jolanta.kusmierczyk@tno.nl, phone: +31 7037407 91, fax: +31 703740654
} 
To account for non-marine particles, a special lognormal mode representing so-called "dust" particles was added to the NAM. The center radius of this $0^{\text {th }}$ mode is at $0.03 \mu \mathrm{m}$ and is not adjusted as function of humidity, because the dust particles are considered to be non-hygroscopic. This dust mode comes into play when the AMP exceeds a value of five. In that case, $30 \%$ of the aerosols of the $1^{\text {st }}$ mode (marine background) are transferred to the dust mode. While this partitioning does not impact heavily on the overall size distribution, it does impact on the aerosol extinction, because the dust particles have a different refractive index than those of marine origin.

Over the years, several improvements have been made to the original NAM. These improvements have focused on the marine aerosol part of NAM, resulting in the addition of a height-dependent large particle mode $\left(4^{\text {th }}\right.$ mode) centered around $8 \mu \mathrm{m}$ (Van Eijk et al., 2002). This version was released as ANAM4. Furthermore, the production mode was reviewed (Van Eijk and Merritt, 2006), as well as the advection mode, which resulted in the introduction of the fetch as a new input parameter (Van Eijk and Kusmierczyk-Michulec, 2007). Fetch accounts for the distance an air mass has travelled over water and allows taking into account the build-up of a marine aerosol concentration as the air mass advects out over the sea. These improvements have been released in the ANAM5 series.

However, these improvements do not address the contribution of non-marine aerosols. Since the early 90s it is known that the performance of NAM is significantly reduced in the coastal zone (Van Eijk and De Leeuw, 1992). The reduced performance arises from the rapid and drastic variation of the aerosol concentration and composition in the coastal zone, which is inadequately modeled by NAM. NAM only considers a 2-component aerosol mixture (marine and dust-like) and the AMP is not well enough related to meteorological observables to account for the variations in concentration. This marginal relation of the AMP to meteorological observables has bothered the NAM user community, because NAM users did not know how to set the AMP. Consequently, there have been requests to replace the AMP by a more accessible parameter. Piazzola et al. (2003) developed the Mediterranean extinction code (MEDEX), in which the AMP is replaced by fetch. While this code can reasonably well predict the aerosol concentrations in the coastal zone, the code only considers marine aerosols. This implies that the extinction calculations will be off when there is a sizable fraction of non-marine aerosols.

The present contribution addresses the non-marine aerosols in (A)NAM and the AMP. A new approach is suggested which involves the introduction of two types of non-marine aerosols and the replacement of the AMP by the Ångström coefficient (Ångström, 1929). The latter parameter can be obtained from fitting the spectral aerosol extinction or aerosol optical thickness spectrum by a power law function. It can be directly measured and has a physical relation to the aerosol

size distribution. Moreover, the Ångström can be regarded as an indicator of the atmospheric aerosol composition in a well- mixed atmospheric boundary layer (Kusmierczyk-Michulec, 2009). Thus, it is a good replacement for the AMP. The replacement of the AMP will result in the release of ANAM6.

\section{METHODOLOGY}

\subsection{Aerosol size distribution and related optical parameters}

The aerosol number size distribution for a given aerosol type can be presented by the following equation, where $r$ is the particle radius, $r_{n}$ is the median radius and $\sigma$ is the standard deviation:

$$
N(r)=\frac{N_{n}}{r \sigma \sqrt{2 \pi}} \exp \left\{-\frac{\left(\ln r-\ln r_{n}\right)^{2}}{2 \sigma^{2}}\right\}
$$

The alternative representation is the volume size distribution, with the volume median radius $r_{v}$ and the standard deviation $\sigma$ : 
$V(r)=\frac{C_{v}}{r \sigma \sqrt{2 \pi}} \exp \left\{-\frac{\left(\ln r-\ln r_{v}\right)^{2}}{2 \sigma^{2}}\right\}$

where $\mathrm{C}_{\mathrm{v}}$ and $\mathrm{N}_{\mathrm{n}}$ are particle concentration for the volume and number size distribution, respectively.

The relation between the volume concentration and the number concentration is given by the following equation:

$$
C_{v}=\frac{4}{3} \pi N_{n} \exp \left(\frac{9}{2} \sigma^{2}\right) r_{n}^{3}
$$

The spectral optical coefficient, called the extinction coefficient ext ( $\lambda$ ) (in $\mathrm{km}^{-1}$ ) can be calculated from the number size distribution (or alternatively from the volume size distribution):

$$
\operatorname{ext}(\lambda)=\pi \int_{r_{\min }}^{r_{\max }} r^{2} Q_{\text {ext }} \frac{d N(r)}{d \ln r} d \ln r
$$

where $\lambda$ is wavelength, $r$ is radius and $\mathrm{Q}_{\mathrm{ex}}$ is the extinction efficiency factor, being a function of the complex index of refraction (Mie, 1908).

The extinction coefficient integrated over the whole column of atmosphere is a dimensionless parameter known as the aerosol optical thickness $\left(\tau_{\mathrm{a}}\right)$ :

$$
\tau_{a}(\lambda)=\int_{H_{\min }}^{H_{\max }} \operatorname{ext}(\lambda, h) d h \approx \int_{H_{\min }}^{H_{\max }} \operatorname{ext}(\lambda) f(h) d h
$$

where $f(h)$ represents the vertical distribution of aerosols, $h$ is the altitude in $\mathrm{km}, H_{\min }$ and $H_{\max }$ are the lower and the upper altitude, respectively, at which a given aerosol type can be found.

The variation of the extinction coefficient with the wavelength can be presented in the form of a power law function (Ångström, 1929):

$$
\operatorname{ext}(\lambda)=\gamma_{c} \lambda^{-\alpha}
$$

The same relation is also valid for the aerosol optical thickness,

$$
\tau_{a}(\lambda)=\gamma_{\tau} \lambda^{-\alpha}
$$

where $\gamma_{c}$ and $\gamma_{\tau}$ are constant and $\alpha$ is the Ångström coefficient (also known as Ångström exponent or Ångström parameter). Usually, this parameter is determined in the spectral range from $440 \mathrm{~nm}$ to $870 \mathrm{~nm}$.

\subsection{Modelling the aerosol mixture in the coastal zone}

In the coastal zone, the aerosol type usually observed is a mixture of sea-salts (SSA) and anthropogenic salts (WS). The mixture may also contain some organic carbon (OC) or black carbon (BC) (Kusmierczyk-Michulec, 2009). These aerosols of continental/industrial origin (e.g. WS, BC) are easily transported by air masses and mixed with the marine aerosols (SSA).

The optical properties of the aerosol mixture can be represented by the aerosol extinction (see eq.4) or by the aerosol optical thickness (see eq. 5). Both parameters can be modeled using the external mixing approach. This means that each aerosol component of a given mixture is represented by a different substance with its own single mode size distribution 
and single complex index of refraction. The spectral values of the aerosol extinction for a given aerosol component are found from Mie calculations. The aerosol optical thicknesses are obtained as the corresponding weighted averages of the extinction coefficients using the volume percentages. This approach is widely used in aerosol models (e.g. McClatchey et al. 1984). Changes in the extinction of hygroscopic aerosols (i.e. SSA or WS) caused by changes in the relative humidity (RH) can be modeled using the approach described by Tang (1996).

For the purpose of this study we will consider the aerosol mixture consisting of SSA, WS and BC. We are aware that these three components do not capture the full variability of the aerosol composition in the coastal zone, but we have selected WS and BC since these two have the greater impact on extinction. In contrary to the first two aerosol components (SSA and WS) which are hygroscopic, the latter aerosol component (BC) is assumed to be insoluble. The parameters of the single mode number size distributions are the following: $r_{n}=0.4, \sigma=0.51$ for SSA, $r_{n}=0.05, \sigma=0.46$ for WS and $r_{n}=0.0118, \sigma=0.3$ for BC. The refractive indices of sea-salts, anthropogenic salts and black carbon are taken from McClatchey et al. (1984).

Since some aerosol components are hygroscopic, the general equation for the aerosol optical thickness of a mixture must be written as (Kusmierczyk-Michulec, 2009):

$$
\tau_{a}(\lambda, R H)=\sum_{j=1}^{3} C_{V}^{j}(R H) \frac{e x t^{j}(\lambda, R H)}{\varsigma_{V}^{j}(R H)}=\sum_{j=1}^{3} C_{V}^{j}(R H) \psi^{j}(\lambda, R H)
$$

where $j$ symbolises the aerosol components SSA, WS and BC. The parameter $\psi^{j}$ indicates the aerosol extinction of the $j^{\text {th }}$ component with respect to its volume concentration $\varsigma_{V}^{j}\left(\mu \mathrm{m}^{3} / \mathrm{cm}^{3}\right)$. The parameter $C_{V}^{j}\left(\mu \mathrm{m}^{3} / \mu \mathrm{m}^{2}\right)$ is the total volume of the $j^{\text {th }}$ aerosol component in the whole column of the atmosphere.

Alternatively, equation (8) can be written in the following form:

$$
\tau_{a}(\lambda, R H)=C_{V}^{t o t}(R H) \times\left\{\frac{C_{V}^{W S}(R H)}{C_{V}^{t o t}(R H)} \psi^{W S}(\lambda, R H)+\frac{C_{V}^{S S A}(R H)}{C_{V}^{t o t}(R H)} \psi^{S S A}(\lambda, R H)+\psi^{B C}(\lambda) \frac{C_{V}^{B C}}{C_{V}^{\text {tot }}(R H)}\right\}
$$

where $C_{V}^{\text {tot }}$ is the total volume of all aerosols in the whole column:

$$
C_{V}^{t o t}=C_{V}^{S S A}+C_{V}^{W S}+C_{V}^{B C}
$$

The relative humidity $(\mathrm{RH})$ modifies the optical properties of not only the hygroscopic aerosol mixtures but also of mixtures containing certain amounts of non-hygroscopic aerosols, such as black carbon. Therefore, the relative contribution of black carbon, $C_{V}^{B C} / C_{V}^{t o t}$, will also be a function of the relative humidity.

Changes in the content of the aerosol components cause the resultant aerosol optical thickness (eq. 9) to change as well. The addition of a small amount of anthropogenic salt or black carbon causes the optical properties of the aerosol mixture to differ significantly from those of the pure sea salts; as a result, the Ångström coefficient is much higher than that of the pure sea-salt components. The dependence of the Ångström coefficient on the aerosol mixture (and humidity) can be exploited as shown by Kusmierczyk-Michulec (2009).

Equation (9) has been used to make a series of simulations for the specific aerosol mixture consisting of sea-salts (SSA), anthropogenic salts (WS) and black carbon (BC), representing the coastal zone. Figure 1 shows the results of these 
simulations, in terms of volume contributions $C_{V}^{j} / C_{V}^{\text {tot }}$ versus Ångström coefficient. The range of Ångström coefficients runs from 0.2 (clean marine air) to 2.2 (heavily polluted air). Figure 1C shows that the SSA fraction dominates the clean marine air (volume contribution of 0.95 ), whereas SSA is virtually absent in the heavily polluted air. In accordance with this, Figures 1A, 1B and 1D illustrate that an increase of the non-marine aerosol contribution leads to an increase in the Ångström coefficient values. The maximum contribution of BC does not exceed 30\%, which is in agreement with measurements (e.g. Kusmierczyk-Michulec et al., 2001). Figure 1D illustrates the case that the anthropogenic salt and black carbon gradually replace the amount of sea-salt. Since both anthropogenic salt particles and black carbon particles are much smaller than sea-salt particles, the number of particles in this particular mixture effectively increases and the resultant volume decreases. As a result the Ångström coefficient increases.

A)

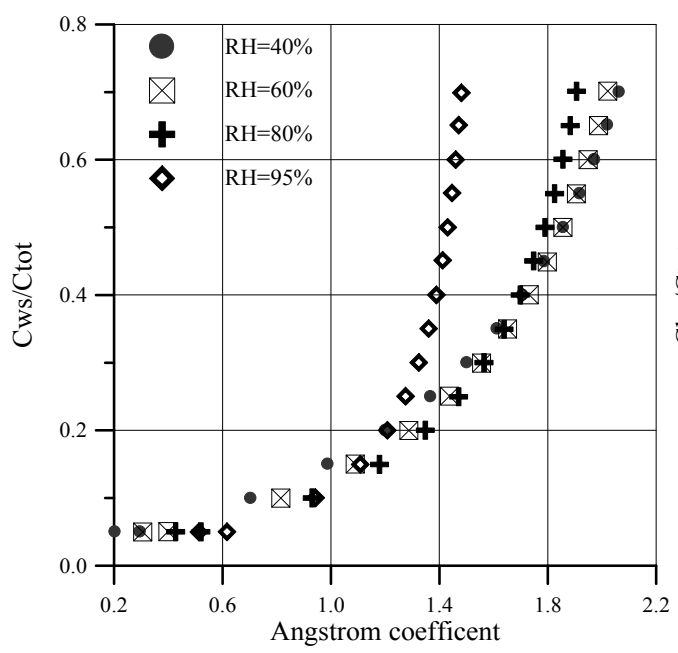

C)

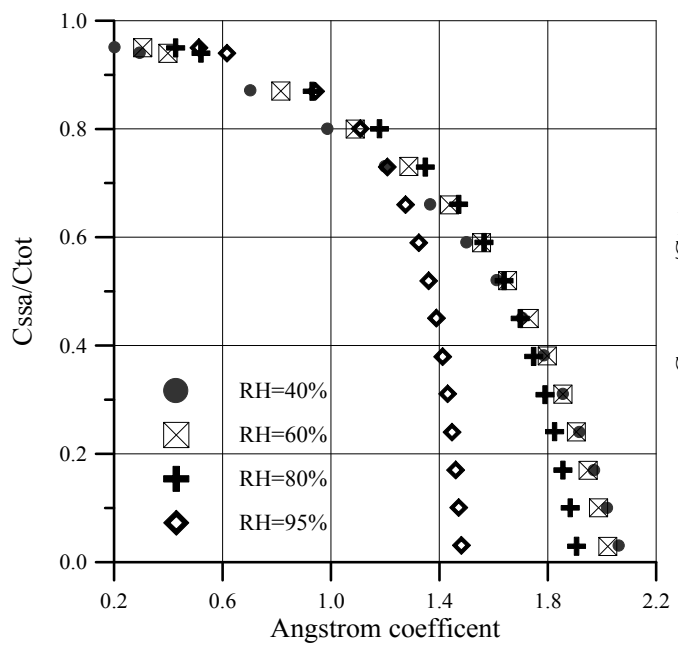

B)

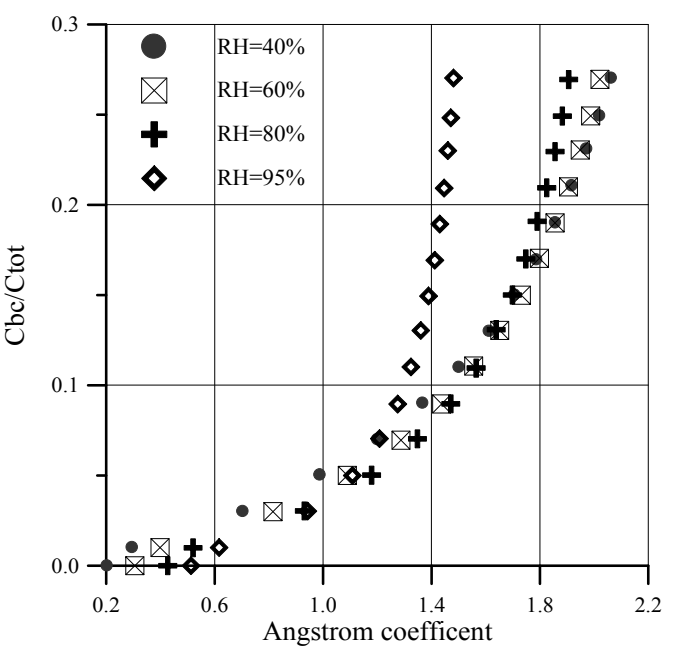

D)

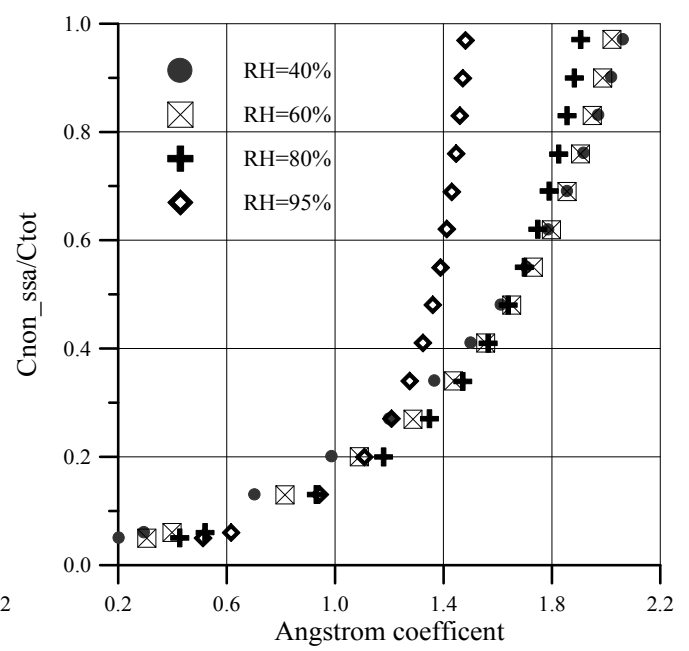

Figure 1. Relations between Ångström coefficients and the aerosol volume contributions. Results of simulations are presented for the following values of relative humidity: $40 \%, 60 \%, 80 \%$ and $95 \%$. A) WS component, B) BC component, C) SSA component and D) non-marine (WS\&BC) component.

The volume contribution of a single component of the aerosol mixture can be expressed in terms of the Ångström coefficient. The results of simulations (Kusmierczyk-Michulec, 2009, and Figure 1) have been fitted to $5^{\text {th }}$ order 
polynomials, one polynomial for each aerosol component and each humidity (12 polynomials in total), resulting in the following relations:

$$
\begin{aligned}
& \frac{C_{V}^{B C}}{C_{V}^{\text {tot }}(R H)}=\sum_{i=0}^{5} A_{i}^{B C}(R H) \times \alpha^{i} \\
& \frac{C_{V}^{W S}(R H)}{C_{V}^{\text {tot }}(R H)}=\sum_{i=0}^{5} A_{i}^{W S}(R H) \times \alpha^{i} \\
& \frac{C_{V}^{S S A}(R H)}{C_{V}^{\text {tot }}(R H)}=\sum_{i=0}^{5} A_{i}^{S S A}(R H) \times \alpha^{i}
\end{aligned}
$$

Where $A_{i}^{B C}, A_{i}^{W S}$ and $A_{i}^{S S A}$ are the coefficients of the $5^{\text {th }}$ degree polynomials. Once the volume contribution is known, the number contribution can be deduced using eq. 3 .

Thus, changes in the composition of the aerosol mixture or relative humidity lead to changes in the aerosol optical thickness and in consequence to changes in the Ångström coefficient values. Therefore, the latter parameter, which can be easily measured, can be used to retrieve information about the aerosol composition. This allows us to replace the AMP by Angstrom coefficient, as we will see in chapter 3 .

\subsection{Fetch dependence}

As the air mass advects out over the sea, the concentration of aerosols of non-marine origin will gradually decrease due to deposition. Consequently, the volume contributions of WS and BC decrease, and hence, the Ångström coefficient. To account for the changes in the aerosol concentration caused by only dry deposition as function of fetch X [m], a simplified equation (Seinfeld and Pandis, 1998) can be used:

$$
C_{V}^{B C}=C_{V, X=0}^{B C} \exp \left(-\frac{V_{d}^{B C} \times X}{B L \times U}\right)
$$

Where $C_{V, X=0}^{B C}$ is the initial volume concentration of black carbon estimated at the coastal station, $V_{d}^{B C}$ is the size dependent deposition velocity in $[\mathrm{m} / \mathrm{s}], B L$ is the height of the boundary layer $[\mathrm{m}]$ and $U$ is the wind speed in $[\mathrm{m} / \mathrm{s}]$. Analogically, a similar equation can be written for the anthropogenic component, WS:

$$
C_{V}^{W S}=C_{V, X=0}^{W S} \exp \left(-\frac{V_{d}^{W S} \times X}{B L \times U}\right)
$$

Since both aerosol components, i.e. BC and WS, consist of particles with sizes less that $1 \mu \mathrm{m}$ in diameter we can assume that both deposition velocities, i.e. $V_{d}^{B C}$ and $V_{d}^{W S}$ are approximately equal to $0.001 \mathrm{~m} / \mathrm{s}$ (e.g. Slinn and Slinn, 1980). 
The effect of different BL depths and dry deposition velocities on the decrease of the aerosol concentrations was demonstrated by Kusmierczyk-Michulec and Van Eijk (2007). It was shown that the smaller BL depth in winter results in a more pronounced decrease, which is in agreement with the measurements.

\section{THE ÅNGSTRÖM COEFFICIENT AND ANAM}

\subsection{Relation between AMP and Ångström coefficient}

In the original NAM, a larger value of the Air Mass Parameter (AMP) flagged a more polluted air mass. As we have seen in the previous sections, the presence of pollution leads to a higher value of the Ångström coefficient, which suggests a relation between AMP and Ångström coefficient. Figure 2 shows that this relation indeed exists. To this end, we explored a dataset consisting of 6000 meteorological data records. For each record, we calculated the aerosol extinction values in the spectral range between $400 \mathrm{~nm}$ and $850 \mathrm{~nm}$, using ANAM4 (with AMP and $0^{\text {th }} / 1^{\text {st }}$ modes). The exercise was repeated for several values of AMP. Next, using equation (6), the Ångström coefficient was calculated.

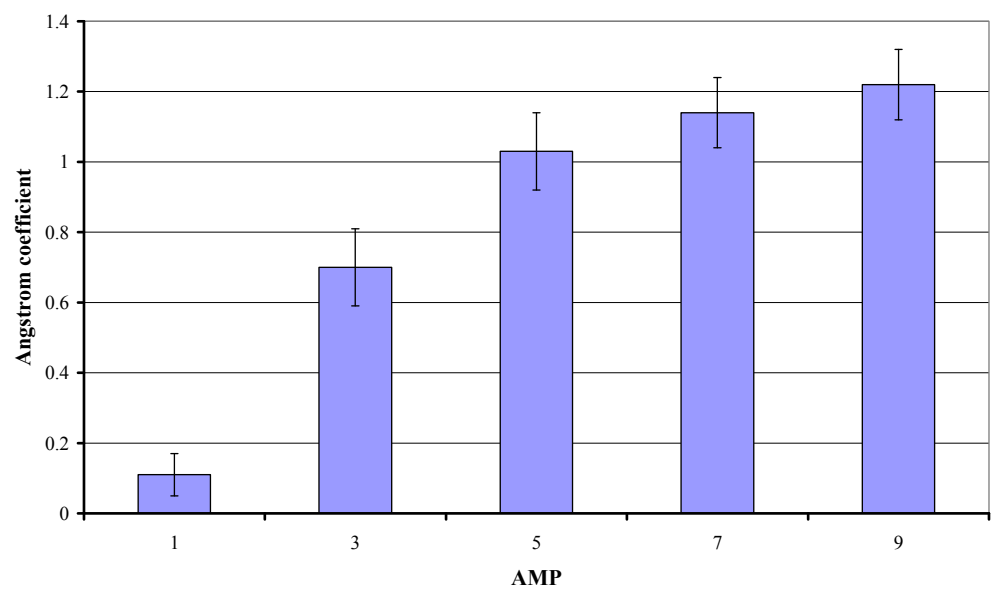

Figure 2. Relation between the AMP and the Ångstrom coefficient.

Figure 2 suggests that a simple relation between Ångström coefficient and AMP can be established. This relation could be used to replace the AMP by Ångström coefficient as input parameter to the ANAM. The advantage of using the Ångström coefficient instead of AMP is that the first one is a physical parameter which can be easily measured. On board of a ship it can be measured by a relatively cheap, hand-held sun photometer (provided that the sun is visible). When no measurements can be made, the value of the Ångström coefficient may be estimated using the public-access AERONET (the Aerosol Robotic Network) network. The worldwide network of ground-based sun photometers called AERONET (Holben et al., 1998) performs passive measurements of aerosols at more than 300 locations all over the world. AERONET stations use CIMEL sun photometers to measure the spectral values of the aerosol optical thickness which are used to estimate the Ångström coefficient. The instantaneous measurements of the Ångstrom coefficient are available on-line. One can thus retrieve the Ångström coefficient from the nearest AERONET station, or another station that is considered representative for the location of interest.

The individual AERONET measurements are also accumulated to build a climatology of Ångström coefficients for each station. These climatologies are also available on-line and can be downloaded to create a climatology look-up table of Angström coefficients. When a particular station is down, or when there is no access to internet, the look-up table can be used to estimate a reasonable value for the Ångström coefficient at the location of interest. 


\subsection{Parametrization of ANAM6}

The relation between AMP and Ångström coefficient shown in Figure 2 allows us to eliminate the AMP as an input parameter to NAM, but leaves us with the limited representation of aerosol composition, i.e., dust-like ( $0^{\text {th }}$ mode) and marine $\left(1^{\text {st }}\right.$ mode). The theoretical framework outlined in the previous section also allows us to go one step further and to replace these two modes by three modes: BC, WS and SSA. This new version of ANAM will be known as ANAM6.

In ANAM6, the dust-like mode $\left(0^{\text {th }}\right.$ mode $)$ and marine background mode $\left(1^{\text {st }}\right.$ mode $)$ are replaced by two lognormals corresponding to $\mathrm{BC}$ and WS. The Ångström coefficient and the relative humidity are subsequently used with equations (11) and (12) to determine the volume concentrations of these two modes, which also yields the volume concentration of SSA, since the total volume concentration $C_{V}^{\text {tot }}$ is normalized.

The above procedure only yields relative concentrations of BC, WS and SSA that need to be converted in absolute mode amplitudes. The absolute amplitude is determined by relating the volume concentration of SSA to the $2^{\text {nd }}$ mode (aged marine aerosols). This mode is centred on $0.24 \mu \mathrm{m}$, which is close to the centre radius of the SSA lognormal used in the simulations by Kusmierczyk-Michulec (2009). Therefore, we assume that the amplitude of the $2^{\text {nd }}$ mode represents the amplitude of the SSA mode. The absolute amplitude of the $2^{\text {nd }}$ mode is calculated as function of wind speed and fetch (Van Eijk and Kusmierczyk-Michulec, 2007) and thus provides the gauge for the relative amplitudes of SSA, BC and WS.

The aerosol distribution thus calculated represents the relative contributions of SSA, BC and WS for the location at which the Ångström coefficient was measured. If necessary, the aerosol distribution can subsequently be displaced with respect to fetch using equations (14) and (15) to account for the deposition of the non-marine aerosols.

\subsection{Current status}

The development of ANAM6 is not yet finished. Two important tasks remain, one of these related to the parameterisation and the other to empirical tuning. As for the parameterisation, the set of equations (11)-(13) should not be used outside their domain of validity. However, in pure marine air masses, the Ångstrom coefficient may drop below 0.2 (and even attain negative values). In that case, the contributions of BC and WS are virtually zero (as suggested by Figure 2), which would imply that there is a very small number of particles with diameters less then $0.1 \mu \mathrm{m}$. However, all experimental evidence suggests that such particles are abundant even in pure marine air; hence the marine background $\left(1^{\text {st }}\right)$ mode in NAM. One might thus envisage the reintroduction of the $1^{\text {st }}$ mode in ANAM6. In that case, the $\mathrm{BC}$ and WS modes replace the $0^{\text {th }}$ mode and the SSA fraction would be contained in modes 1 and 2 . This would necessitate a new gauge for fixing the absolute amplitudes of the SSA, BC and WS volume fractions.

The final parameterization of ANAM6 (with or without the marine background mode) will be established by comparison with experimental data: aerosol size distributions and transmission measurements. These efforts are currently underway and will be reported elsewhere.

\section{CONCLUSIONS}

The new approach presented in this paper suggests replacement the ill-defined air mass parameter (AMP) in the Advanced Navy Aerosol Model by the Ångström coefficient. The advantage is that the latter parameter can be directly measured and has a physical interpretation. The Ångström coefficient can be measured on board of a ship by a hand-held sun photometer, it can be estimated using the measurements from the nearby coastal AERONET station or deduced from the climatology dataset, available also from AERONET. When the particle size distribution is dominated by small particles, usually associated with pollution, the Ångström coefficients are high; in clear conditions they are usually low. The set of equations described in this paper allows estimating the contribution of non-marine particles. Therefore the Ångström parameter is a good tracer of the aerosols originated over land and hence a good replacement for the AMP. 


\section{REFERENCES}

1. Ångström, A., "On the atmospheric transmission of sun radiation and on dust in the air". Geogr. Ann., 11, 156166, (1929).

2. Bohren, C.F., and D.R. Huffman, “Absorption and Scattering of Light by Small Particles”, 550 pp., John Wiley, New York, (1983).

3. Gathman, S.G., "Optical properties of the marine aerosol as predicted by the Navy Aerosol Model", Opt. Eng., 22, 57-62, (1983).

4. Holben, B. N., T.F. Eck, I. Slutsker, D. Tanre, J.P. Buis, A. Setzer, E. Vermote, J.A. Reagan, Y.J. Kaufman, T. Nakajima, et al., "AERONET-A Federated Instrument Network and Data Archive for Aerosol Characterization". Remote Sensing of Environment, 66(1):1-16, (1998).

5. Kneizys, F.X., L.W., Abreu, G. P. Anderson, J.H. Chetwynd, E.P. Shettle, A. Berk, L.S. Bernstein, D.C. Robertson, P. Acharya, L.S. Rothman, J.E.A. Selby, W. O. Gallery and S. A. Clough, "The Modtran 2/3 report and Lowtran 7 model", Philips Laboratory PL/GPOS, Hanscom AFB, MA, (1996).

6. Kusmierczyk-Michulec, J., "Ångström coefficient as an indicator of the atmospheric aerosol type for a wellmixed atmospheric boundary layer: Part 1: Model development”, Oceanologia, 51(1), p.5-39, (2009).

7. Kusmierczyk-Michulec J., Schulz M., Ruellan S., Krüger O., Plate E., Marks R., de Leeuw G., Cachier H., "Aerosol composition and related optical properties in the marine boundary layer over the Baltic Sea", J. Aerosol Sci. 32 (8) pp. 933-955, (2001).

8. Kusmierczyk-Michulec J. and A.M.J. van Eijk, "Ångström coefficient as a tracer of the continental aerosols", Proceedings SPIE vol. 6708-25, Atmospheric Optics: Models, Measurements, and Target-in the-Loop Propagation, 27-28 August 2007, San Diego, CA, USA, (2007).

9. McClatchey, R. A., H. -J. Bolle, K. Y. Kondratyev, J. H. Joseph, M. P. McCormick, E. Raschke, J. B. Pollack, D. Spänkuch, and C. Mateer, "A preliminary cloudless standard atmosphere for radiation computation", report, 53 pp., Intl. Radiat. Comm., Boulder, Colo., (1984).

10. Mie, G., Annales de Physics, 25, 377-445, (1908).

11. Piazzola, J., F. Bouchara, de Leeuw, G. and A.M.J. van Eijk, "Development of the Mediterranean extinction code (MEDEX)", Optical Engineering, 42, 912-924, (2003).

12. Seinfeld, J., and S. Pandis, Atmospheric Chemistry and Physics: From Air Pollution to Climate Change, Wiley, (1988).

13. Slinn, S.A., and W.G.N. Slinn, "Predictions for particle deposition on natural waters", Atmos. Environ., 14, 1013-1016, (1980).

14. Tang I.N., "Chemical and size effects of hygroscopic aerosols on light scattering coefficients", J. Geophys. Res., 101 (D14), 19245-19250, (1996).

15. Van Eijk, A.M.J. and D.L. Merritt, "Improvements in the Advanced Navy Aerosol Model (ANAM)", SPIE Proceedings, 6303, (2006).

16. Van Eijk, A.M.J., and G. De Leeuw, "Modeling aerosol extinction in a coastal environment", SPIE Proceedings, 1688, 28-36, (1992).

17. Van Eijk, A.M.J. and J. Kusmierczyk-Michulec, "Review of the marine modes in ANAM". TNO report, TNODV 2007 C382, (2007).

18. Van Eijk, A.M.J., L.H. Cohen, L.J. Navarro and G. De Leeuw. "Near-surface aerosol transmission in the marine environment". SPIE Proceedings 4884, 160-169, (2002). 